\title{
WORKSHOP PERENCANAAN PEMBELAJARAN PENDIDIKAN ANAK USIA DINI BERBASIS LOOSE PARTS
}

\author{
Intan Prastihastari Wijaya ${ }^{1}$, Epritha Kurniawati ${ }^{2}$, Veny Iswantiningtyas ${ }^{3}$, Linda Dwiyanti ${ }^{4}$ \\ Prodi. PG-PAUD, FKIP, Universitas Nusantara PGRI Kediri ${ }^{1234}$ \\ e-mail : intanwijaya@ unpkediri.ac.id ${ }^{1}$, epritha@unpkediri.ac.id ${ }^{2}$, veny@ unpkediri.ac.id ${ }^{3}$, \\ lindadwiyanti@unpkediri.ac.id ${ }^{4}$
}

\begin{abstract}
Abstrak
Pembelajaran Pendidikan Anak Usia Dini bertujuan untuk membantu anak dalam menggapai tahapan perkembangannya, sehingga diperlukan perencanaan pembelajaran. Guru Pendidikan Anak Usia Dini dituntut untuk mampu merancang dan mengembangkan serta melaksanakan kegiatan pembelajaran yang sesuai dengan karakteristik perkembangan perserta didik. Workshop ini memiliki tujuan untuk meningkatkan pemahaman dan keterampilan guru Taman Kanak-kanak di Kabupaten Kediri dan sekitarnya dalam membuat rencana pembelajaran berbasis loose parts. Workshop ini diikuti oleh 127 peserta, adapun materi workshopnya adalah perencanaan perencanaan pembelajaran berbasis losse parts. Hasil dari workshop yaitu $80 \%$ peserta dapat membuat perencanaan pembelajaran anak usia dini berbasis loose parts.
\end{abstract}

Kata kunci: perencanaan pembelajaran, pendidikan anak usia dini, losse parts.

\begin{abstract}
Early Childhood Education Learning aims to assist children in reaching their developmental stages, so learning planning is needed. Early Childhood Education Teachers are required to be able to design and develop and implement learning activities that are in accordance with the characteristics of the development of students. This workshop aims to improve the understanding and skills of kindergarten teachers in Kediri and surrounding areas in making loose parts based learning plans. The workshop was attended by 127 participants, while the workshop material was a learning plan based on losse parts. The results of the workshop that $80 \%$ of participants can make early childhood learning planning based on loose parts.
\end{abstract}

Keywords: learning planning, early childhood education, losse parts.

\section{PENDAHULUAN}

Pembelajaran merupakan suatu sistem yang terdiri dari perencanaan, pelaksanaan dan evaluasi. Pada sistem tersebut saling berinteraksi satu dengan yang lainnya, apabila salah satu sistem tersebut mengalami masalah maka akan mempengaruhi yang lain, sehingga proses pembelajaran tidak akan berjalan dengan baik. Agar pembelajaran memiliki kualitas yang bagus, maka guru dihadapkan pada tantangan bagaimana caranya menyusun rencana pembelajaran yang sistemnya saling mendukung sehingga akan tercipta suasana pembelajaran yang menyenangkan bagi anak dan anak menjadi senang untuk belajar. Perencanaan pembelajaran Pendidikan Anak Usia Dini merupakan langkah awal yang sangat penting untuk memberikan arah yang tepat dalam pelaksanaan proses pembelajaran, selain itu rencana pembelajaran disusun untuk memberikan panduan dalam menyiapkan kegiatan pembelajaran yang sesuai dengan kemampuan anak.

Menurut Moeslichatoen (2004) bahwa pelaksanaan pembelajaran anak usia dini dilakukan berdasarkan prinsip-prinsip sebagai berikut : 1) Berorientasi pada kebutuhan anak, 2) Belajar melalui bermain, 3) Kegiatan belajar mengembangkan dimensi kecerdasan secara terpadu, 4) Menggunakan pendekatan klasik, kelompok, dan individual, 5) Lingkungan kondusif, 6) Menggunakan berbagai model pembelajaran, 7) Mengembangkan keterampilan hidup dan hidup beragam, 8) Menggunakan media dan sumber belajar, 9) Pembelajaran berorientasi kepada prinsip perkembangan dan belajar anak. Namun dalam membuat perencanaan pembelajaran, terdapat 
beberapa kendala, antara lain: 1) umumnya kualifikasi guru PAUD bukan dari ke-PAUD-an. 2) harapan sebagian besar orang tua tidak sejalan dengan filosofi pendidikan untuk anak usia dini. 3) sejumlah lembaga PAUD didominasi oleh kepentingan personal yang tidak memihak pada kepentingan anak sebagai sasaran didik. Secara empiric sering sekali ditemukan guru memposisikan anak usia dini tidak ubahnya seperti anak yang belajar di jenjang menengah, perannya sebagai pendengar dan pelaksana tugas. Guru memposisikan gurunya sebagai pengajar yang mengembangkan pembelajaran secara akademik.

Latif, M dan Zukhairina (2013) menjelaskan ada beberapa lesson plan yang dibuat guru antara lain : 1) Leson plan / LP satu tahun, merupakan rencana pembelanjaran yang dibuat oleh guru dalam merencanakan kegiatan pembelajaran untuk satu tahun atau dua semester, biasanya LP satu tahun meliputi tema satu tahun. 2) Lesson plan satu semester, merupakan pembelajaran yang dibuat oleh guru dalam merencanakan kegiatan pembelajaran untuk satu semester, biasanya LP satu tahun meliputi tema dan sub tema atau topik yang akan dibahas selama satu semester. 3) Lesson plan tiap tema, merupakan rencana pembelajaran yang dibuat oleh guru dalam merencanakan kegiatan pembelajaran untuk satu semester, biasanya LP setiap tema harus mengandung prinsip-prinsip dari rencana pembelajarn itu sendiri yang akan dibahas selama pemakaian tema tersebut. 4) Lesson Plan harian, merupakan rencana pembelajaran yang dibuat oleh guru untuk merancang kegiatan pembelajaran untuk satu kali pertemuan, biasanya LP setiap tema harus mengandung prinsip-prinsip dari rencana pembelajaran itu sendiri yang akan dibahas selama pemakaian tema tersebut dalam satu kali pertemuan. Ada beberapa hal yang perlu dipersipkan dalam menyusun perencanaan pembelajaran pada pendidikan anak usia dini. Menurut Mulyasa (dalam Farida, 2017) dalam pengembangan rencana pembelajaran dinyatakan bahwa perencanaan pembelajaran PAUD meliputi perencanaan semester, rencana Pelaksanaan Program mingguan (RPPM), dan rencana pelaksanaan program harian (RPPH).

Pada jenjang Pendidikan Anak Usia Dini, kegiatan pembelajarannya dikemas dalam bentuk bermain. Putri (2019) Permainan yang sekarang masih hangat di kalangan pendidikan anak usia dini yang berfungsi untuk merangsang kemampuan bermain pembangunan anak adalah Loose Parts Play. Loose Parts Play adalah sebuah permainan yang menggunakan bahan yang dapat dipindahkan, dibawa, digabungkan, dirancang ulang, disejajarkan, dipisahkan dan disatukan kembali dengan berbagai cara. Bahan tersebut adalah bahan yang dapat dipergunakan dengan mandiri maupun dikombinasikan dengan bahan lain. Bahan ini dapat berasal dari bahan alami maupun sintetis. Contohnya : batu, tunggul, pasir, kerikil, kain, ranting, kayu, palet, bola, ember, keranjang, krat, kotak, kotak, batang kayu, batu, bunga , tali, ban, bola, cangkang dan biji polong. Anak dapat membangun suatu tempat maupun membuat suatu kegiatan melalui imajinasi mereka dengan bahan-bahan yang telah tersedia.

Konsep pembelajaran menggunakan bahan alam sebagai pembelajaran kreatif juga dilakukan penelitian oleh Wahyuningsih (2020) penerapan metode STEAM menggunakan loose parts dalam pelaksanaan pembelajaran dapat meningkatkan kreativitas anak ditandai dengan anak mampu memecahkan masalah dan mampu membuat hubungan dengan lingkungan sekitar. Selain itu hasil studi literasi yang dilakukan oleh Nugraheni (2019) tujuan dari pembelajaran STEAM berbasis loose parts pada pendidikan anak usia dini adalah mewujudkan pemikiran ilmiah dan kreatif sejak dini.

Pembelajaran menggunakan konsep loose parts dapat menjadi salah satu strategi untuk anak dalam mengembangkan berbagai keterampilan dibandingkan menggunakan mainan buatan pabrik. Sebagai contoh daun dapat dijadikan sebagai uang, tongkat kayu dijadikan sebagai pedang atau sesuai dengan imajinasinya terhadap bahan-bahan tersebut. Tujuan diadakannya workshop ini adalah untuk mengingkatkan pengetahuan dan keterampilan guru pendidikan anak usia dini dalam membuat rencana pembelajaran berbasis loose parts, selain itu dengan adanya kegiatan workshop ini diharapkan guru pendidik anak usia dini memiliki pengalaman langsung dalam menyusun perangkat pembelajaran berbasis loose parts yang nantinya akan dapat diterapkan di sekolahannya.

\section{METODE}

Workshop perencanaan pembelajaran anak usia dini berbasis loose parts dilaksanakan dengan melibatkan 127 guru Taman Kanak-kanak yang ada di Kabupaten Kediri dan sekitarnya. Kegiatan 
workshop ini dilaksanakan pada tanggal 13 Desember 2019 dengan materi perencanaan pembelajaran Pendidikan Anak Usia Dini berbasis loose parts, adapun deskripsi pelaksanaan kegiatan workshop sebagai berikut:

Sesi Pertama

Pada sesi pertama ini diisi dengan pengampaian materi yang berjudul "perencanaan pembelajaran anak usia dini berbasis loose parts". Peserta perlu diberikan langkah-langkah menyusun RPP sesuai dengan kurikulum 2013, agar semua peserta / guru yang ada di Kabupaten atau Kota Kediri dan sekitarnya memiliki pemahaman yang sama mengenai perencanaan pembelajaran berdasarkan kurikulum 2013. Berbekal pengetahuan tersebut dapat dijadikan sebagai landasan bagi guru / peserta untuk mengembangkan RPP berdasarkan kurikulum 2013 secara mandiri sesuai dengan kebutuhan anak usia dini.

Sesi Kedua

Sesi kedua ini diisi dengan diskusi kelompok dan praktek secara langsung menyusun RPPM dan RPPH pengembangan tema dan merancang pembelajaran berbasis loose parts. Semangat peserta pada kegiatan ini cukup baik, ada beberapa peserta workshop yang masih kesulitan untuk membagi KI dan KD dalam menyusun program semester. Tim Pengabdian Prodi. PG-PAUD, FKIP Universitas Nusantara PGRI Kediri kemudian menyepakai untuk membuat webbing tema, program semester dan RPPH.

Keterbatasan yang dialami oleh peserta cukup wajar karena masih banyak guru TK yang belum paham betul penerapan kurikulum 2013, sehingga ketika akan melaksanakan kurikulum 2013 yang komponennya terdiri dari pengembangan tema, pemetaan KI dan KD dalam program semester, pengembangan RPPM, Penyusunan Tujuan Pembelajaran dan Indikator Pencapaian Pekembangan, pengembangan RPPH. Setelah melalui beberapa diskusi, mulai ditemukan beberapa cara efektif untuk mengembangkan tema, program semester dan RPPH. Dari kegiatan ini diharapkan kesulitankesuliatan yang dihadapi peserta workshop pengembangan RPP kurikulum 2013 ini dapat terselesaikan berdasarkan penjelasan dari narasumber.

\section{HASIL DAN PEMBAHASAN}

Guru Taman Kanak-kanak dituntut untuk memiliki kemampuan merancang kegiatan pembelajaran anak usia dini sesuai dengan kurikulum yang berlaku, dalam merancang kegiatan pembelajaran berupa program tahunan, semester, mingguan dan harian guru harus mampu mengembangkan tema sesuai dengan kebutuhan anak usia dini. Hal tersebut sesuai dengan pedoman perencanaan pembelajaran Anak Usia Dini tahun 2014. Kurikulum yang dikembangkan oleh beberapa guru Taman Kanak-kanak di Kabupaten Kediri dan sekitarnya sudah sesuai dengan pedoman tersebut yaitu mengembangkan tema dengan berpikir saintifik, akan tetapi belum semua guru mampu mengembangkan tema berbasis loose parts, hal ini dapat dipahami karena masih banyak guru yang belum pernah secara mandiri mengembangkan RPP.

Sesuai Direktorat Pembinaan PAUD 2014 tentang kurikulum PAUD terdiri dari perencanaan program semester berupa pengembangan tema, RPPM, RPPH. Beberapa guru Taman Kanak-kanak yang ada di Kabupaten Kediri dan sekitarnya sudah mengembangkan tema sesuai dengan kurikulum yaitu berpikir saitifik, akan tetapi belum semua guru mampu mengembangkan tema berbasis loose parts. Hal tersebut dapat dipahami karena selama ini masih banyak guru yang belum secara mandiri mengembangkan RPP sesuai kreatifitasnya.

Sesuai pendapat Steamfli (dalam Nugraheni, 2019), menyatakan bahwa loose parts memberikan kesempatan kepada anak-anak untuk bermain secara bebas dan tidak didominasi oleh peran orang dewasa. Teori ini memberikan wawasan kepada guru tentang bagaimana peran lingkungan luar mendukung anak-anak untuk dapat menciptakan pengalaman bermain yang kaya dan beragam.Pendapat lain dikemukakan oleh Flanningan dan Dietze (dalam Nugraheni, 2019), berpendapat bahwa bermain di lingkungan luar dengan pembelajaran loose parts dapat mendukung anak-anak untuk memiliki tingkat keterlibatan yang tinggi karena memiliki pengaruh positif pada perilaku anak-anak dan perkembangan mereka.

Dengan adanya workshop ini, guru diharapkan dapat lebih banyak mengenalkan loose parts disekitar anak yang dituangkan dalam bentuk kegiatan pembelajaran. Loose parts memiliki 7 jenis yaitu : bahan dasar alam, plastik, logam, penggunaan kembali kayu dan bamboo, kaca dan 
keramik, benang dan kain, bekas kemasan. Berbagai tema berbasis loose parts dapat dikembangkan dalam bentuk tema loose parts, tema tanaman, tema pertania, tema rekreasi dan sebagainya. Implementasi pembelajaran loose parts akan lebih tampak pada rancangan RPPH. Dalam rancangan RPPH, tampak beberapa kegiatan bermain yang bernuansa loose parts. Berikut ini beberapa dokumentasi desain pembelajaran berbasis loose parst yang sudah dipraktikkan oleh peserta.

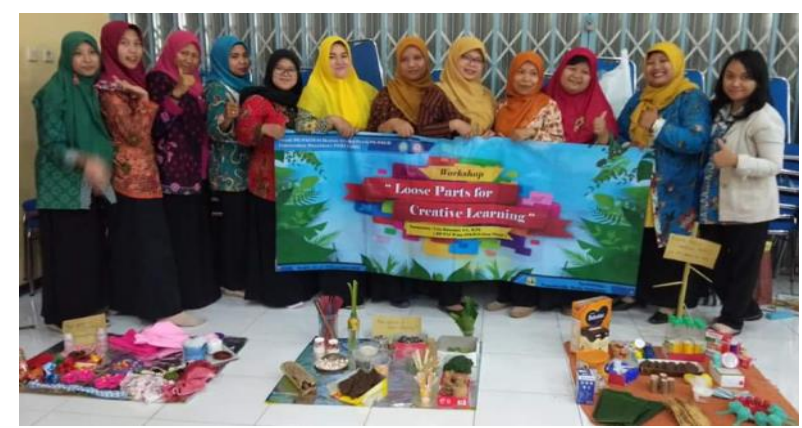

Gambar 1 : Praktik Langsung Desain Pembelajaran Kreatif loose parts

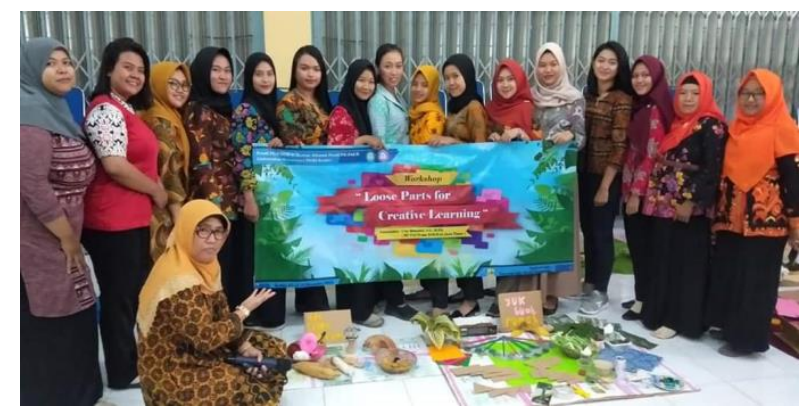

Gambar 2: Praktik Langsung Desain Pembelajaran Kreatif loose parts

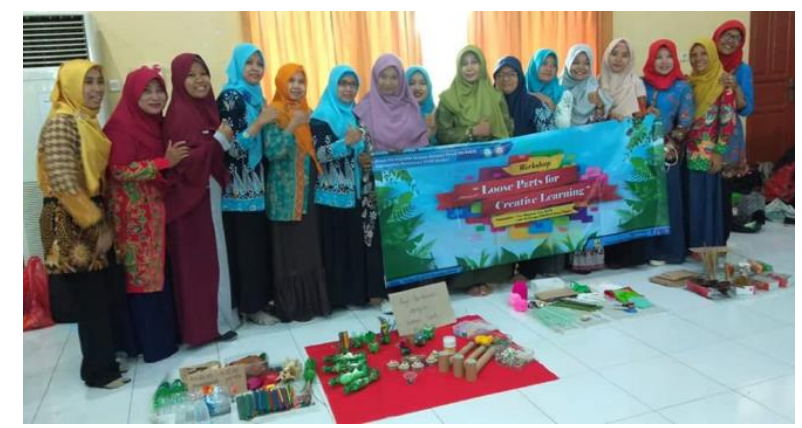

Gambar 3 : Praktik Langsung Desain Pembelajaran Kreatif loose parts

Panitia wokshop menyusun acara dengan menarik, sehingga semua peserta bersemangat mengikuti acara dari awal sampai akhir. Setelah narasumber menyampaikan materi, peserta langsung praktek menuangkan ide kreatifnya untuk menciptakan rancangan pembelajaran yang bersumber dari bahan loose parts yang nantinya akan dapat dipraktekkan di lembanganya masingmasing. Dengan adanya kegiatan workshop ini diharapkan akan memudahkan peserta sekaligus guru PAUD untuk menyusun perencanaan pembelajaran berbasis loose part, sehingga pelaksanaan pembelajaran akan meningkatkan kreatifitas anak yang ditunjukkan anak dapat memecahkan masalah melalui cara membuat hubungan dengan lingkungan sekitarnya.

\section{SIMPULAN}

Workhsop perencanaan pembelajaran pendidikan anak usia dini berbasis loose parts dapat meningkatkan pengetahuan, keterampilan dan kreativitas guru PAUD dalam membuat perencanaan 
pembelajaran yang menjadikan anak memiliki perilaku yang positif dimana anak dapat memecahkan permasalahnya serta mampu membuat hubungan dengan lingkungan sekitarnya.

\section{UCAPAN TERIMA KASIH}

Ucapan terima kasih ditujukan kepada semua pihak khususnya Tim Pengabdian Prodi. PGPAUD, FKIP Universitas Nusantara PGRI Kediri berkerjasama dengan panitia Ikatan Alumi PGPAUD, HIMA Prodi. PG-PAUD UNP Kediri, PAUD Lab. School Universitas Nusantara PGRI Kediri, dan seluruh peserta yang telah bekerjasama dari awal sampai akhir sehingga kegiatan dapat terlaksana dengan lancar.

\section{DAFTAR PUSTAKA}

Nugraheni, Alfrida Dewi. (2019). Penguatan Pendidikan Bagi Generasi Alfa Melalui Pembelajaran Steam Berbasis Loose Parts Pada PAUD. Prosiding Seminar Nasional Pendidikan dan Pembelajaran 2019 "Reorientasi Profesionalisme Pendidik dalam Menghadapi Tantangan Revolusi Industri 4.0". Hal. 512-518. Universitas Muhammadiyah Ponorogo, 29 Agustus 2019.

Farida, Siti. (2017). Pengelolaan Pembelajaran Pendidikan Anak Usia Dini. Wacana didaktika Jurnal Pemikiran, Penelitian Pendidikan dan Sains. Vol. 5 No.2 Desember 2017. Halaman 189-200. Pamekasan: Fakultas Keguruan dan Ilmu Pendidikan Universitas Islam Madura.

Latif, M dan Zukhairina. (2013). Orientasi Pendidikan Anak Usia Dini : Teori dan Aplikasi. Jakarta : PT. Fajar Interpratama.

Moeslichatoen. (2004). Metode Pengajaran di TK. Jakarta : Rineka Cipta.

Putri Mirabella, dkk. (2019). Loose Parts Play Menyongsong Kemampuan Main Pembangunan Anak Usia Dini di Era Society 5.0. Seminar Nasional PAUD. 06-122019. Hal. 182-185. Universitas PGRI Semarang. http://conference.upgris.ac.id/index.php/Snpaud2019/article/view/480/359

Wahyuningsih Siti, dkk. (2020). Efek Metode STEAM pada Kreatifitas Anak Usia 5-6 Tahun. Jurnal Obsesi : Jurnal Pendidikan Anak Usia Dini. Vol. 4 Issue. 1 Hal. 295301. 